\title{
LAS UTOPÍAS Y DISTOPÍAS EN LAS MÚSICAS POPULARES DE LA SEGUNDA MITAD DEL SIGLO XX EN EL MARCO DE LOS DISCOS CONCEPTUALES DE POP ROCK
}

\author{
Jorge Marredo Rosa \\ Músico y Doctor en Psicología
}

Resumen: El presente artículo aborda el surgimiento y desarrollo de los discos conceptuales de poprock, en el contexto sociocultural surgido a finales de los años sesenta del siglo XX, se analizan también los cambios tecnológicos que los posibilitaron, así como su definición, clasificación y algunos ejemplos notables de este tipo de discos. Se analiza también el contenido utópico y distópico que con frecuencia incluyen.

Palabras claves: utopías, distopía, música conceptual, rock progresivo, ópera rock, mundos imaginados, contracultura, psicodelia, 1968, historia del rock, cultura popular.

Dystopias, utopias and imagined worlds in popular music of the second half of the twentieth century in the context of the concept albums of Pop-Rock

Abstract: This article deals with the emergence and development of conceptual pop records in the sociocultural context emerged in the late sixties, technological changes that enabled are also analyzed, as well as its definition, classification and some notable examples of this kind of records. The utopian and dystopian content of this type of disc is also analyzed.

Key words: utopias, dystopias, conceptual music, progressive rock, rock opera, imagined worlds, counterculture, psychedelia, 1968, rock history, popular culture.

Hacia la segunda década de los años sesenta de pasado siglo XX, diferentes circunstancias históricas, socioculturales y económicas propician que las músicas populares de consumo masivo, originariamente destinadas al baile y entretenimiento de adolescentes y jóvenes, empiecen a incorporar elementos cultos a su narrativa, dando así lugar a intentos de acercar estas músicas al contexto artístico y a dar mayor protagonismo a la creación de las mismas y al acto de escucharlas. Cómo indica Frith (1987) con respecto al estudio estético de la música popular, esta es vista con frecuencia como carente de interés porque está condicionada por las fuerzas sociales, mientras que la música culta

Data de recepció: 17 de maig de 2019 / Data d'acceptació: 30 d'agost de 2019. 
tendría, en teoría, un discurso tan potente que puede transcenderlos. Siguiendo a este autor asumiremos que tal distinción es tan social y política cómo otras muchas y que la música popular puede tener discursos artísticos particulares y dignos de estudio e investigación más allá de las cuestiones puramente socioculturales, si bien estas, y como no podría ser de otra forma, han tenido un peso importante en el origen y mantenimiento de dichas aspiraciones.

\section{DEL OTIUM AL NEGOTIUM. ASPECTOS SOCIOCULTURALES}

La recuperación económica europea tras la segunda guerra mundial hace que vaya apareciendo de forma progresiva un mercado de ocio destinado exclusivamente a la juventud y que a diferencia de otros intentos anteriores, como por ejemplo en los años 20, este no esté destinado en exclusiva a clases sociales altas (Hormigos y Martín, 2004). A lo anterior cabe añadir que el nivel formativo de la población y el número de universitarios aumenta, haciéndolo también con ello el nivel cultural generacional, tanto en EE.UU. como en buena parte de Europa (Brenner, 2003).

De acuerdo con esta situación la industria del entretenimiento emprende una estrategia destinada a aumentar el valor económico del ocio y progresivamente a mostrar modelos que representan los valores deseables en la juventud de clase media, a saber, rebeldía, individualidad y consumo cultural (Rubio y Kanelliadou, 2009). Esta estrategia termina influyendo profundamente en la forja de la identidad de las generaciones siguientes y en los movimientos contraculturales que no tardan en afianzarse en la juventud, reforzados por los intensos momentos políticos que empiezan a darse en la década de los sesenta y que se consolidan con los distintos acontecimientos ocurridos a lo largo del año 1968 (Papallini, 2017).

Previamente, el modelo de juventud rebelde lo van exponiendo en sus libros los autores de la Generación Beat, especialmente Allen Ginsberg, Williams Burroughs o Jack Kerouac. En sus libros, se presenta un modelo de juventud formada; universitaria o al menos culta; inquieta y en búsqueda continua de nuevas sensaciones, ya sea a través del consumo de drogas o por los viajes por otros países e inmersos, en la mayoría de los casos, en un intenso consumo cultural. Es en este modelo donde se encuentra gran parte del germen de la contracultura, esto es el planteamiento de formas de vida alternativas separadas del modelo anglosajón de clase media; y cristaliza con la aparición de los beatniks, máximos representantes de este estilo de vida e introductores, entre otros aspectos, del culto a la ciudad, de la música jazz y las drogas en el nuevo modelo de rebeldía (Rex, 1975). 
Daniel Bell expone algunos de estos aspectos de la siguiente forma:

El hecho era que, por la década de 1950, la cultura norteamericana se había hecho primariamente hedonista, interesada en el juego, la diversión, la ostentación y el placer, y todo ello -típicamente de Norteamérica- de una manera compulsiva (2004: 77).

El paso de esta cultura del hedonismo asociada al consumo originada en norteamérica, e inicialmente circunscrita a las clases más favorecidas, a Europa se produce según Robert Bocock:

Hacia 1950 y siguiendo el modelo ya establecido en los Estados Unidos, primero en Inglaterra y después en el resto de Europa occidental, el "consumo de masas", en un sentido próximo al moderno, comenzó a desarrollarse entre todas las clases sociales exceptuando las más pobres (2003: 38).

Así el escenario anterior va dibujando de generación en generación la consolidación del modelo rebelde de juventud asociada a unas formas de consumo muy específicas y diferenciadoras, haciendo que toda la generación que crece entre los años cincuenta y los sesenta, empiece a desarrollar un sentido y necesidad de ocio que termina siendo absorbido en el desarrollo de la propia identidad y de lo que significa ser joven, primero en occidente y más adelante a nivel global (Romaní y Sepulveda 2005; Heath y Potter, 2005; Herrera, 2017).

Casi al mismo tiempo que el colonialismo occidental se va debilitando en sus formas más duras, las generaciones venideras van adoptando y permitiendo la adopción de otras formas culturales tanto de dentro como de fuera de los países occidentales (Herrera, 2017). Por un lado, el surgimiento de los movimientos de liberación racial en EE.UU. hacen que las músicas "negras" (blues, jazz, soul, etc.) vayan siendo aceptadas y llegando de forma masiva a los jóvenes de clase media primero de EE.UU. y después de Europa, para allí pasar al resto de occidente (Romaní y Sepulveda, 2005). Por otro lado, se produce la asimilación de ciertos elementos de orientalismo, misticismo oriental y chamanismo precolombino que terminan desembocando en la llamada cultura psicodélica (Heath y Potter, 2005).

El término psicodelia, traducido del original inglés de psychedelia, es acuñado por el psiquiatra norteamericano Humphry Osmond en 1956 en el contexto de sus usos terapéuticos con el LSD (Farber, 2002; Usó-Arnal, 2010); haciendo referencia a la subcultura surgida en torno al orientalismo y las drogas. Así en este contexto surgirán a principios de la década de los sesenta una serie de pensadores y escritores difusores de la expansión de la conciencia que tendrían una enorme influencia posterior a través de sus libros, conferencias y 


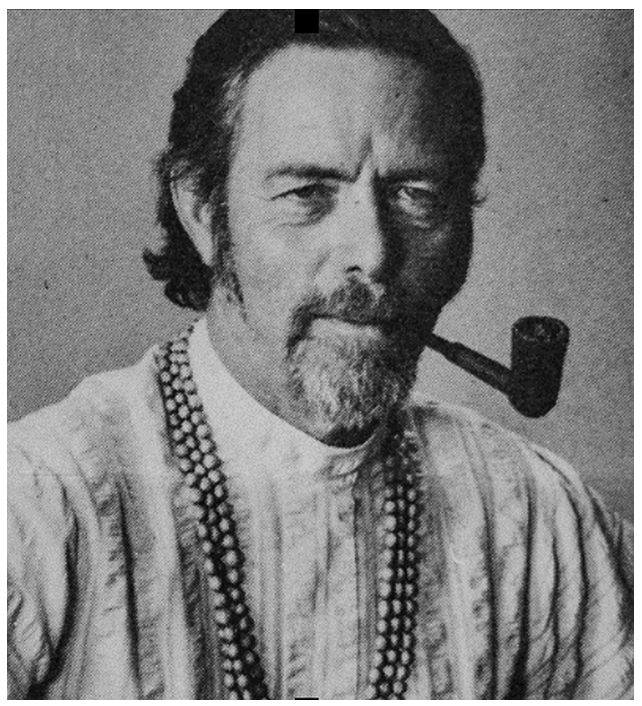

Imagen 1. Fundación Alan Watts, fotógrafo sin acreditar (1970): Retrato de Alan Watts.

talleres. Nombres como el de Allan Watts y Timothy Leary, se vuelven referentes de la contracultura y poco a poco van calando en el imaginario juvenil (Heath y Potter, 2005). (Imagen 1).

Cabe señalar que la consolidación de la era espacial y el escenario de la Guerra Fría hacen que la ciencia ficción, ya sea mediante el cine, la literatura y el comic, formen también parte del bagaje cultural de estas generaciones (Rodríguez, 2010). En este escenario y en las obras de esta temática el espacio exterior y los encuentros con los extraterrestres se presentan como vía de cambio potencial para la humanidad o como amenaza, es decir como lugar de encuentro entre planetas o como castigo por el comportamiento humano (Francescutti, 2004).

\section{INFLUENCIA DE LOS ASPECTOS SOCIOCULTURALES EN LA MÚSICA POP ROCK Y SURGIMIENTO DE LA TEMÁTICA UTÓPICA Y DISTÓPICA EN LA MISMA}

Dado lo expuesto hasta ahora no es difícil deducir que la música, dada su importancia en el ocio juvenil, empezase a ocupar un espacio central en el nuevo modelo de juventud rebelde, de forma que el desarrollo del mercado destinado a ello va cobrando fuerza para dar respuesta a esa necesidad mer- 
cantilizada de rebeldía previamente vendida por las industrias del ocio (Hormigos y Martín, 2004).

En este marco sociopolítico y en respuesta al nuevo modelo de juventud la industria musical empieza a dar rienda suelta a las inquietudes de grupos y solistas musicales que empiezan a dar calado cultural y político a sus creaciones, artistas de gran alcance como los Beatles o Bob Dylan hacen que las ambiciones y aspiraciones artísticas de toda una generación de músicos se vayan elevando de forma proporcional a la que sus propuestas eran aceptadas por el gran público (Hegarty y Halliwell, 2011). De esta forma los sencillos ritmos del rock and roll original y de la música pop se empiezan enriquecer con estéticas procedentes del jazz, la música clásica y contemporánea o las músicas étnicas tanto no occidentales como la música hindú o la africana; así cómo occidentales, como el folk o el blues, dando lugar a estilos más sofisticados (Macan, 1997; Martin, 2015; Rose, 2015). Por otro lado, las letras de las canciones van ganado peso a la hora de transmitir esta nueva cultura, ya sea para hablar de injusticias sociales, política, experiencias con drogas o las nuevas formas de convivencia (Hernandez, 2006).

Con tal bagaje, no es raro que surja la necesidad de un "no hay tal lugar" (Ainsa, 1999; Moro, 2006), es decir de un utopísmo casi endógeno que caracteriza a gran parte de esta generación. La utopía como régimen estatal ideal está sin duda en gran parte de las formas de vida alternativa que van siendo anunciadas y que alcanzan el zénit con el movimiento Hippie (Baltar, 2011).

Frente a este pensamiento utópico está el distópico, el cual sería la consecuencia futura de la sociedad de entonces si no cambia sus hábitos consumistas producto de un capitalismo desaforado. La utopía como solución y la distopía como castigo serán argumentos recurrentes en los discos conceptuales que se desarrollarán pocos años después (Rhodes, 2007; Baltar, 2011). Encontramos pues que el mundo imaginado utópico es el antídoto frente al mundo contemporáneo que conduce a la distopía.

\section{ASPECTOS INDUSTRIALES Y TECNOLÓGICOS}

\section{El disco de 33 rpm como soporte}

Patmore (2009) expone que el disco de vinilo de $33 \mathrm{rpm}$ de dos caras surge como tal en 1948, siendo denominado como Long Play, de ahí sus conocidas siglas LP; y siendo desarrollado por Columbia Records, quién también desarrolla un formato de $45 \mathrm{rpm}$, conocido como Single más económico y normalmente con una canción por cada cara. Desde entonces y hasta bien entrada 


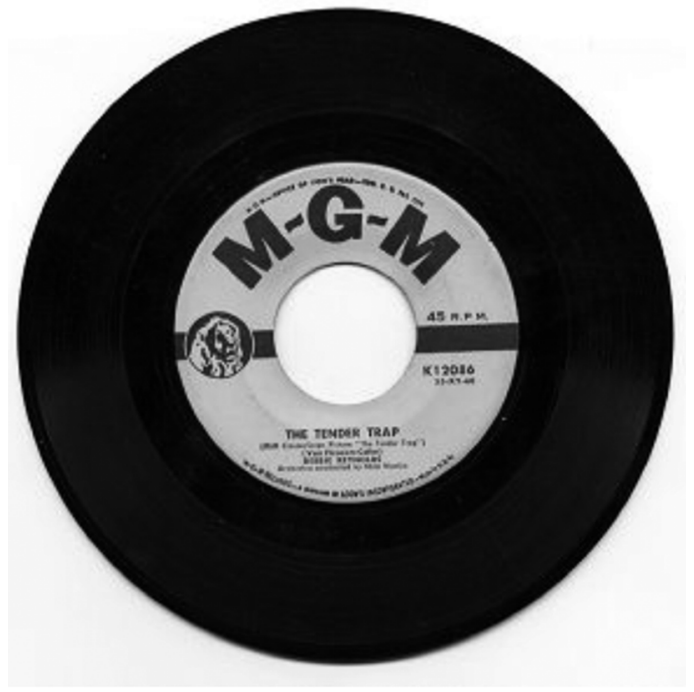

Imagen 2. Daniel P. B. Smith (2004): Disco single de 45 RPM de 1956.

la década de los 80 del siglo XX, el LP reina en el mercado musical como formato de referencia cuando es destronado por el disco compacto o CD (Bartmanki \& Woodward, 2015). Posteriormente el CD será sustituido por la aparición y distribución en internet del formato de compresión mp3 y más adelante el mp3 será sustituido a su vez por el streaming (Medel, 2014). Cabe apuntar que la cultura DJ, vinculada a la música electrónica de baile y a los clubs, es quizás la máxima responsable de que el formato LP no se extinguiera durante los años 90 (Brewster \& Broughton, 2010) y continúe hasta bien entrado el siglo XXI (Imagen 2).

\section{La portada del disco como reclamo y complemento del disco conceptual}

De forma paralela a este desarrollo del LP, se va produciendo el de las portadas de los mismos y estas van cobrando más importancia en su desarrollo, primero como reclamo comercial y después como parte del contenido conceptual del disco traduciéndolo al lenguaje visual, López (2014). Si bien en un principio la finalidad de la portada era principalmente protectora y neutra, la portada ilustrada fue la idea del diseñador, de nuevo de Columbia Records, Alex Steinweiss en 1939 con la finalidad de transmitir un mensaje afín a la 
música y obviamente de atraer a nuevos consumidores. Según Heller (citado en Medel), estas primeras portadas eran:

representaciones simbólicas y muy atractivas de jazz, música clásica o popular, diseñadas a la manera de los carteles publicitarios europeos modernos (2014:10).

El desarrollo de la complejidad musical de los discos y de la factura cada vez más artística de las portadas avanzan de forma pareja desde principios de los años sesenta hasta finales de los años setenta del pasado siglo, cuando la aparición de nuevos estilos como el punk y la new wave, menos complejos desde el punto de vista musical, hacen que las portadas adopten una estética más realista y sobria acorde con estas propuestas musicales (Anysley, 2001).

Durante gran parte de la década de los setenta y durante esta transición de modas, así como ante la carencia de otros medios de promoción, el propio embalaje del disco se convierte en reclamo, surgiendo portadas dobles, troquelados, distintas versiones de las portadas, etc. (Medel, 2014).

\section{Refinamiento de la producción musical}

El rápido crecimiento de la industria del entretenimiento hace que esta pueda invertir en el desarrollo tecnológico de la industria fonográfica, así por ejemplo hace que los tocadiscos portátiles, más conocidos cómo gramófonos, puedan disminuir sus costes y su tamaño, de manera que junto con la consolidación de la radio, hacen que la industria musical se convierta, junto con el cine y la televisión, en una de las principales vías de entretenimiento. Por ejemplo, se calcula que con la aparición del nuevo formato del LP en 1948 se produjo un incremento del $894 \%$ en las ventas de discos (McKnight-Trotz y Steinweiss, 2000).

Para autores como Rose (2015), la aparición del formato estereofónico y la experimentación que este permite en la producción musical influyen de forma evidente en la forma de presentar la música y en el desarrollo del disco como concepto en sí mismo. El término estéreo, del griego stéreos, sólido; hace referencia al sonido reproducido por dos canales relacionados, izquierdo y derecho y se diferencia del original utilizado en la industria, denominado monofónico y que sólo usaba un canal de reproducción.

Este formato fue introducido en la producción de discos en 1954 y en las emisiones radiofónicas a partir de 1960, si bien su invención se debe al ingeniero británico Alan Blumlein quien lo patenta en 1933 (Alexander, 2000). 
Todo lo anterior, unido a una mayor inversión en técnicas de producción musical, hace que para la segunda mitad de los años 60 la industria ya esté preparada para ofrecer productos que reflejen todas esas inquietudes de la juventud en forma de contracultura y rebeldía asociada a los hábitos de consumo (Hormigos y Martín, 2004).

\section{Concepto y características del disco conceptual}

$\mathrm{Al}$ tratarse de un ámbito poco investigado desde un punto de vista académico, no cuenta el investigador con muchas definiciones operativas ni taxonomías, como bien indica Elicker (2001), así esta autora expone en su obra sobre todo definiciones del ámbito periodístico. Por ejemplo, cita a Boehm, quien haciendo un ejercicio pragmático define este formato como un esfuerzo en hacer de un simple disco de rock and roll algo más ambicioso en forma de historia, opus o representación. Heckman los concibe como proyectos centrados en un punto de vista específico o materiales relacionados (Elicker, 2001).

El New Oxford Dictionary of English define el disco conceptual como un disco de rock dispuesto en forma de canciones que expresan un tema particular o idea.

Rodriguez Durán (2014) en su investigación sobre las narrativas transmedia entiende el disco conceptual como aquel unificado por una historia que se desarrolla a través de textos, música, elementos visuales y la puesta en escena o performance.

Para Shute (2013) el disco conceptual se caracteriza por introducir ideas no musicales para estructurar un álbum, asegurando que no merece tal definición aquel disco que está compuesto por temas vinculados únicamente por el estilo o el enfoque, desmarcándolo así de la tradición sinfónica clásica.

Ante tanta dificultad quizás sea la definición propuesta por Elicker (2001) la más adecuada para la finalidad de este artículo, definiendo el disco conceptual en el contexto de la música popular como aquel que contiene una trama a través de las canciones, sea esta temática, musical o una mezcla de ambas.

Cómo hemos indicado las definiciones del disco conceptual son pocas, la cosa no mejora con las clasificaciones las cuales son escasas y de poco rigor. Una de las pocas que puedan ser operativas para el investigador es la de Letts (2005), quien propone tres tipos de álbumes conceptuales:

- Narrativo: caracterizado por una trama, tanto implícita, como explícita; así como personajes bien definidos.

- Temático: no presenta una narración, pero sí cohesión temática.

- Resistente: puede presentar elementos de los dos anteriores tipos, el mensaje es más críptico y por tanto menos abierto a una interpretación. 


\section{DESARROLLO HISTÓRICO DEL DISCO CONCEPTUAL}

\section{Antecedentes y primeros intentos de música conceptual popular}

Como hemos comentado con anterioridad el aspecto tecnológico es clave a la hora de entender el surgimiento del disco conceptual y como se ha indicado previamente es a finales de la década de los cuarenta del siglo xx cuando surge el formato adecuado, esto es el LP. Hasta entonces no existía posibilidad para crear discos conceptuales, ya que no existía un formato adecuado y la responsabilidad de las letras y la composición eran dirigidas por los representantes y las propias compañías (Sedláčková, 2015). No obstante, es en este contexto pre-LP en el que surgen los primeros intentos de hacer una música popular más compleja, en concreto es el cantautor Woody Guthrie el que compone y logra publicar Dust Bowl Ballads en 1935. En este trabajo, Guthrie canta sobre las experiencias de los refugiados del Dust Bowl, donde una terrible sequía acompañada de tormentas de polvo empujó a numerosos granjeros del Medio Oeste a emigrar a California (Imagen 3).

En 1955, 20 años más tarde, Frank Sinatra publica In the Wee Small Hours, en el cual narra una noche solitaria y dolorosa debido a un amor perdido, autores como Shute (2013) ven en este trabajo el primero que encaja en la definición de disco conceptual, si bien no parece que originariamente hubiera una intención conceptual por parte del artista (Imagen 4).

En 1964, Johnny Cash, inspirado por Guthrie, publica Bitter Tears (1964) sobre los problemas de los indios nativos americanos.

No obstante en el contexto de la música pop, dentro del panorama sociocultural expuesto anteriormente, no es hasta la segunda década de los años sesenta cuando grupos de gran alcance comercial concretan ese deseo de hacer una música popular de corte más elaborado y culto. Diferentes autores ven en Little Deuce Coupe de los Beach Boys publicado en 1963 y en The Kinks Face to face publicado en 1966 antecedentes del disco conceptual de pop-rock. Cabe indicar que si bien estos trabajos tienen partes que puedan ser consideradas conceptuales, incluyendo "suites" de mayor duración que el resto de los temas, no pueden ser considerados como tales al no tener un hilo conductor el disco en su totalidad (Imagen 5).

\section{Primeros discos conceptuales}

Si hablamos de disco conceptual como tal, el primero con gran alcance y reconocida influencia es sin duda Pet Sounds de los Beach Boys publicado en 


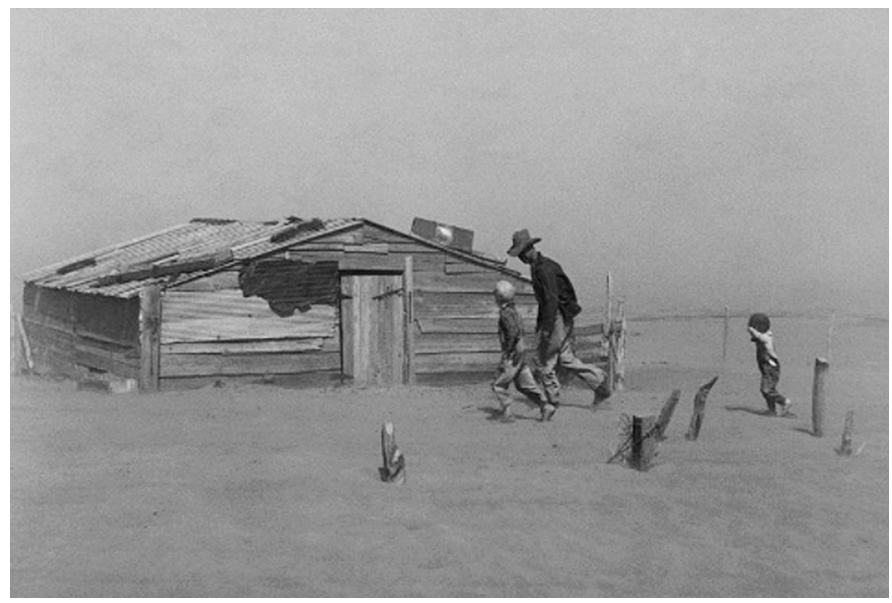

Imagen 3. Arthur Rothstein (1936): Un granjero y sus dos hijos durante una tormenta de arena en Cimarron County, Oklahoma, abril de 1936.

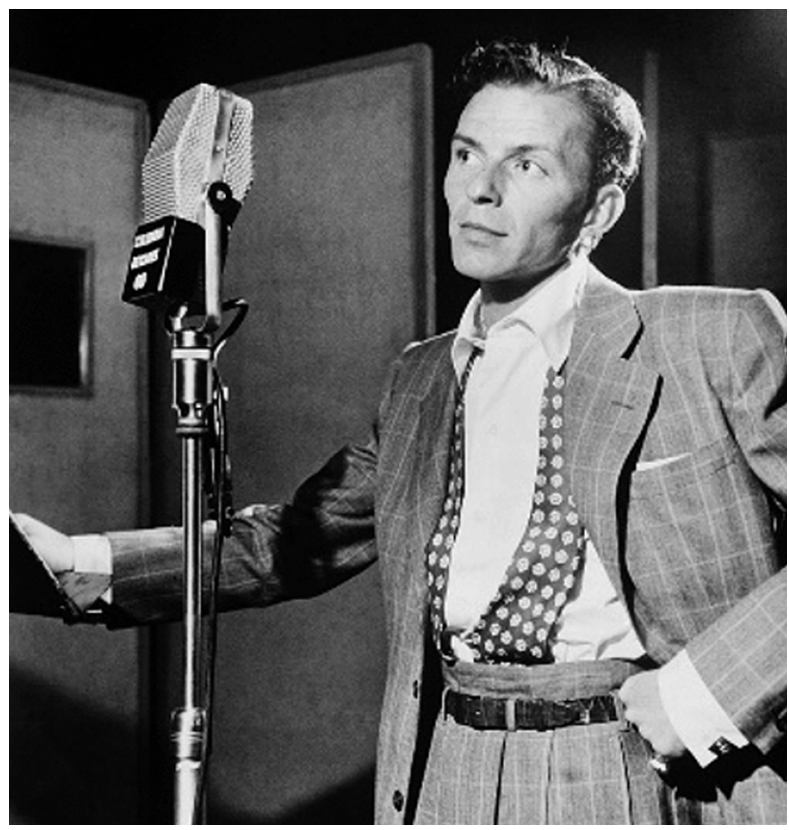

Imagen 4. William P. Gottlieb (1947): Retrato de Frank Sinatra en el Liederkranz Hall, Nueva York. 
Imagen 5. Henrik Ørsted (1966). The Kinks en el Polideportivo de Nordstrand, Suecia.

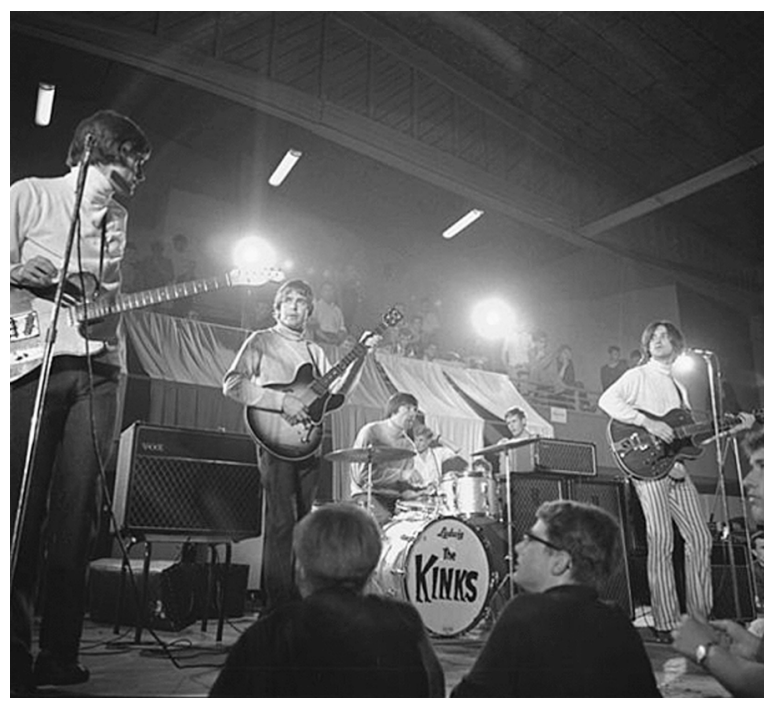

1966. Este disco supone el primer ejemplo de gran producción pop e introduce nuevas técnicas de grabación, armonía y timbre hasta entonces inéditas en este estilo musical. Este trabajo es citado con frecuencia como la mayor influencia del que sería el primer gran disco conceptual, Sgt. Peppers Club Band de los Beatles, publicado en 1967 y seguramente el disco modelo sobre el que otros músicos desarrollan ideas en este nuevo formato artístico. En estos trabajos se empiezan a materializar todas las características de este tipo de trabajo, a saber: experimentación, psicodelia y un hilo narrativo (Sedláčková, 2015). La publicación de Sgt. Peppers Club Band de los Beatles supone un claro punto de inflexión y materializa las aspiraciones artísticas del músico de pop rock de la época (Shute, 2013) (Imagen 6).

Esta nueva visión artística se engrosa con Days of future passed del grupo británico Moody Blues, publicado en 1967 y en el que se narra el devenir de un día cotidiano. Por primera vez una banda pop es acompañada por una orquesta y este trabajo da lugar a la etiqueta de Rock Sinfónico para denominar a aquellos intentos de fusionar música popular con música clásica (Anderton, 2010; Hegarty \& Halliwell; 2011) (Imagen 7).

Dos años después en 1968 se publican más discos que consolidan el formato, Ogdens' Nut Gone Flake de Small Faces y S.F Sorrow de los Pretty Things, que dan lugar a una nueva etiqueta, la de Ópera Rock. No obstante es Tommy del grupo británico The Who el trabajo que da mayor empuje a la eti- 


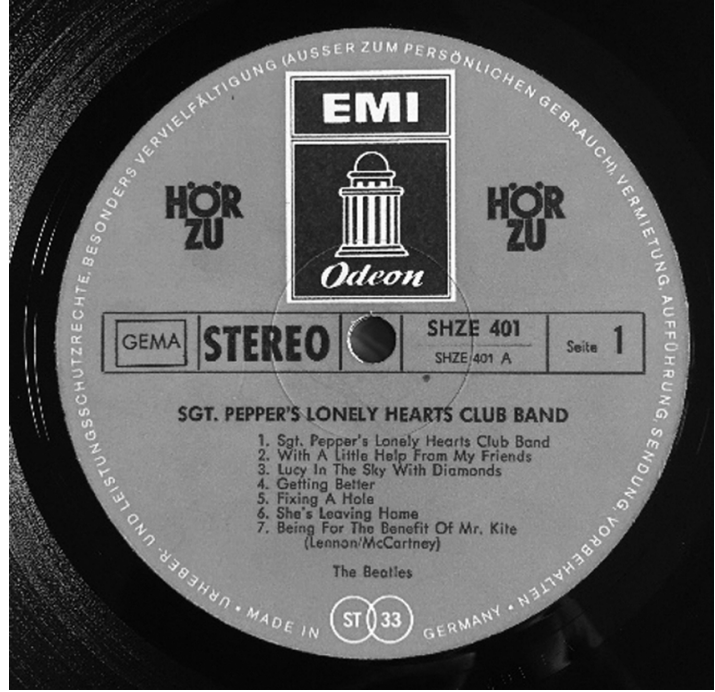

Imagen 6. Karle Horn (1967): Etiqueta de la edición alemana de Sgt. Peppers Club Band de The Beatles.

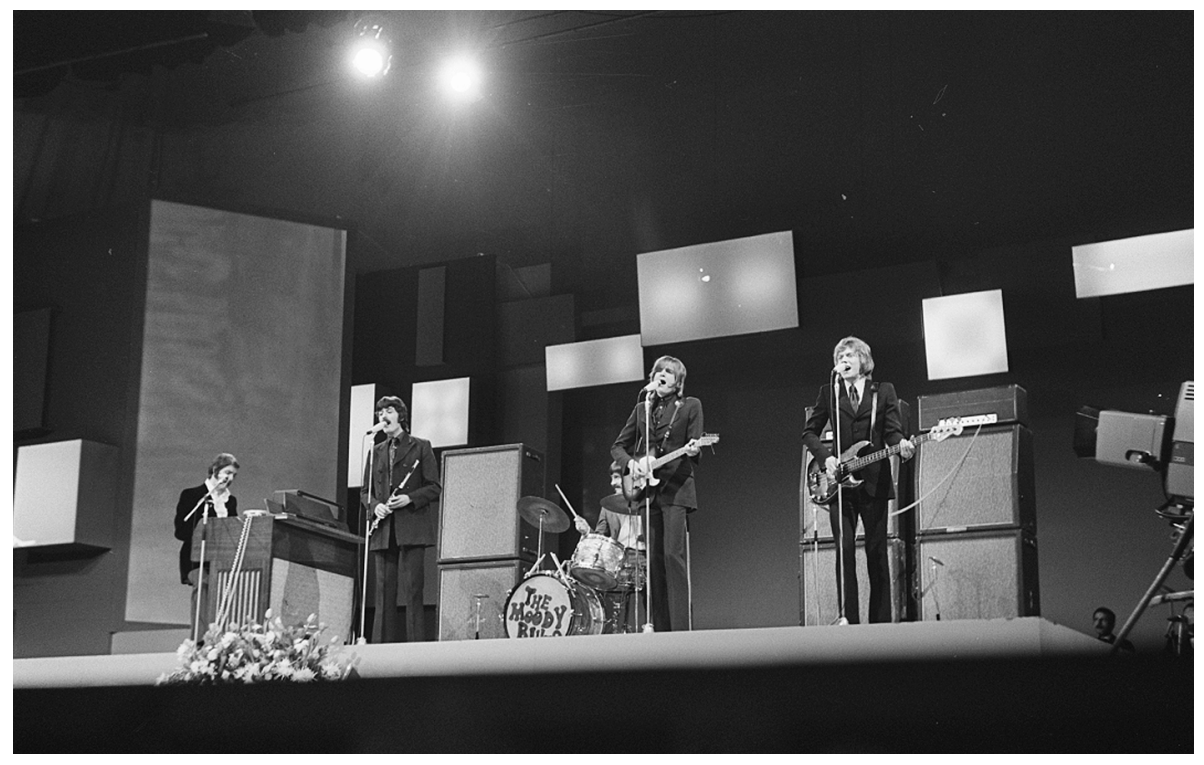

Imagen 7. Fotógrafo desconocido (1969): The Moody Blues en Holanda.

Saitabi. Revista de la Facultat de Geografia i Història, 69 (2019), pp. 203-225 ISSN 0210-9980 DOI: 10.7203/saitabi.69.15948 @) (1) ఆ€ 


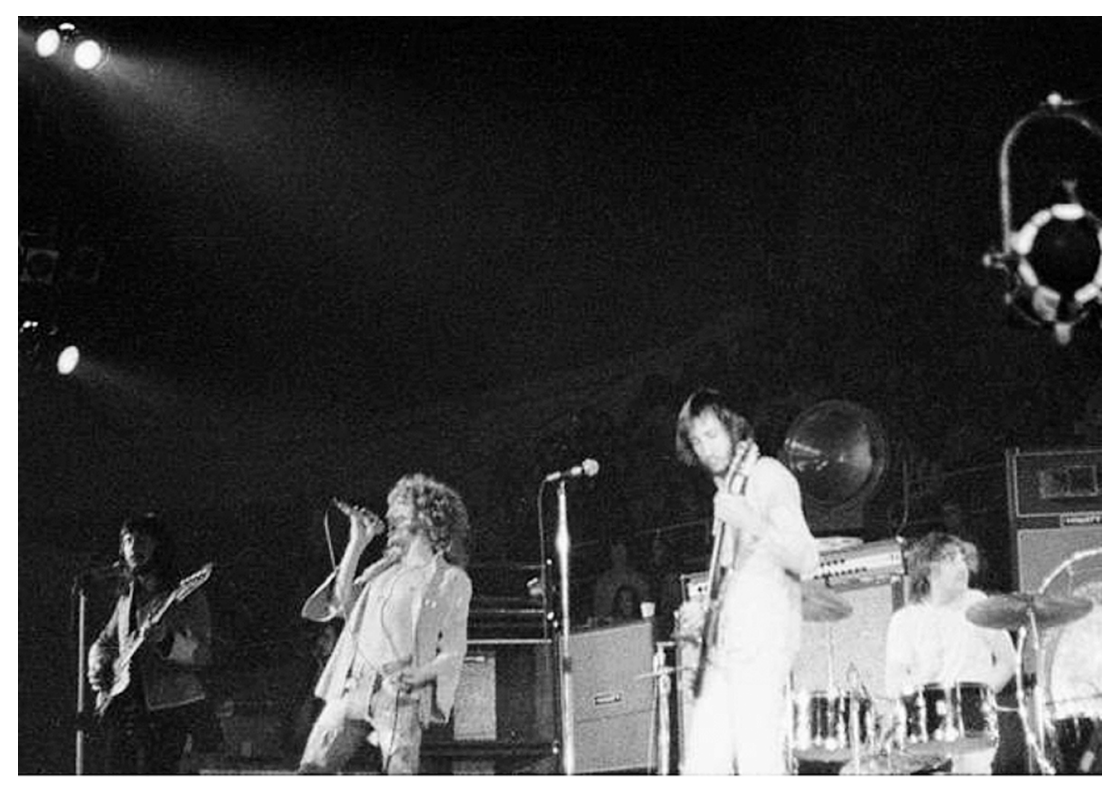

Imagen 8. Hunter-Desportes (1971): The Who en el Coliseo de Charlotte, Carolina del Norte, 20, noviembre, 1971.

queta de ópera rock, además de ser uno de los primeros LP dobles que se publican consolida a este formato como preferente para el disco conceptual. En este trabajo se cuenta la historia de Tommy, un chico que desarrolla sordocegera psicosomática al presenciar como su madre y su amante matan a su padre, de manera que aprende a comunicarse mediante una máquina pinball (Imagen 8).

\section{Desarrollo y consolidación}

A partir de aquí el formato se populariza y se da una edad dorada especialmente dentro de lo que se vino a llamar Rock Progresivo, etiqueta heterogénea que abarca desde los desarrollos más cercanos al romanticismo musical del siglo XIX, conocido como Rock Sinfónico, hasta desarrollos cercanos a las músicas de vanguardia como la electrónica y las músicas repetitivas, como el Krautrock desarrollado en la antigua República Federal Alemana (Josephson, 1992; Anderton, 2010; Hegarty \& Halliwell, 2011). 
Dentro de este momento histórico y cultural no tardan en llegar las primeras adaptaciones literarias de ficción, ya sean Viaje al centro de la tierra de Julio Verne a cargo de Rick Wakeman en 1974; Historias de Misterio e Imaginación de Edgar A. Poe a cargo de Alan Parsons Project en 1976; Un mundo Féliz de Aldeus Huxley, adaptada por el grupo alemán Breve New World en su disco Impressions On Reading Aldous Huxley de 1972; El Ganso de Nieve de Paul Gallico, adaptado por el grupo Camel en su disco The Snow Goose en 1976; La guerra de los mundos de H.G. Wells, adaptado por Jeff Wayne en su disco Jeff Wayne's Musical Version Of The War Of The Worlds de 1978; El Señor de los anillos de J.R.R. Tolkien adaptado por el músico sueco Bo Hanson en 1970; en su disco Music Inspired by Lord of the Rings en Rebelión en la granja y 1984 de George Orwell, adaptados respetivamente por Pink Floyd en Animals, publicado en 1977 y por David Bowie en su disco Diamond Dogs, publicado en 1974.

En estos títulos y en otros muchos, el LP se convierte en una especie de novela musicada en la que tanto la duración de los temas como las portadas (normalmente abiertas) invitan y evocan mundos fantásticos y perdidos. Como se puede observar la distopía literaria encaja a la perfección con la visión distópica de esta generación frente a su posible futuro, por eso los clásicos distópicos ocupan un lugar preferente en estas adaptaciones.

Conforme el formato se va consolidando las temáticas se van volviendo más complejas, como las paradojas de vida moderna en Dark Side of the Moon de Pink Floyd; la propia Biblia por el grupo argentino Vox Dei en 1971; El libro de las revelaciones en 666 del grupo griego Aphrodite's Child publicado en 1973; o los shrutis, textos religiosos sagrados hindúes transmitidos de generación en generación abordados por el grupo Yes en su disco Tale From Topographic Oceans publicado en 1973 en el que el protagonista busca a través de las doctrinas y los mandamientos tener un acercamiento a la "Ciencia Reveladora de Dios"; y a través de los cambios musicales nos podemos dar idea de sus cuestionamientos internos, sus dudas e incertidumbres, pero sobre todo por su constante afán de búsqueda (Imagen 9).

$\mathrm{Al}$ mismo tiempo que otros músicos conciben el disco como una obra de ficción total, en la que música y letra conducen al oyente a una experiencia inmersiva, como es el caso de algunos miembros del ya citado grupo Yes. Así Olias of Sunhillow de Jon Anderson publicado en 1976 cuenta historia de Olias, un alienígena que tras una catástrofe volcánica construye un aparato volador, el Moorglade, con el que realizará un largo viaje para intentar salvar su mundo; o No Earthly Connection de Rick Wakeman, también publicado en 1976, y que trata una historia paralela de la humanidad en la que esta pierde su alma musical porque un traidor la vende a unos alienígenas y esta es castigada por un dios de diferentes nombres. Como vemos en ambos casos, los intentos de alertar sobre una humanidad descontrolada son más que evidentes. 


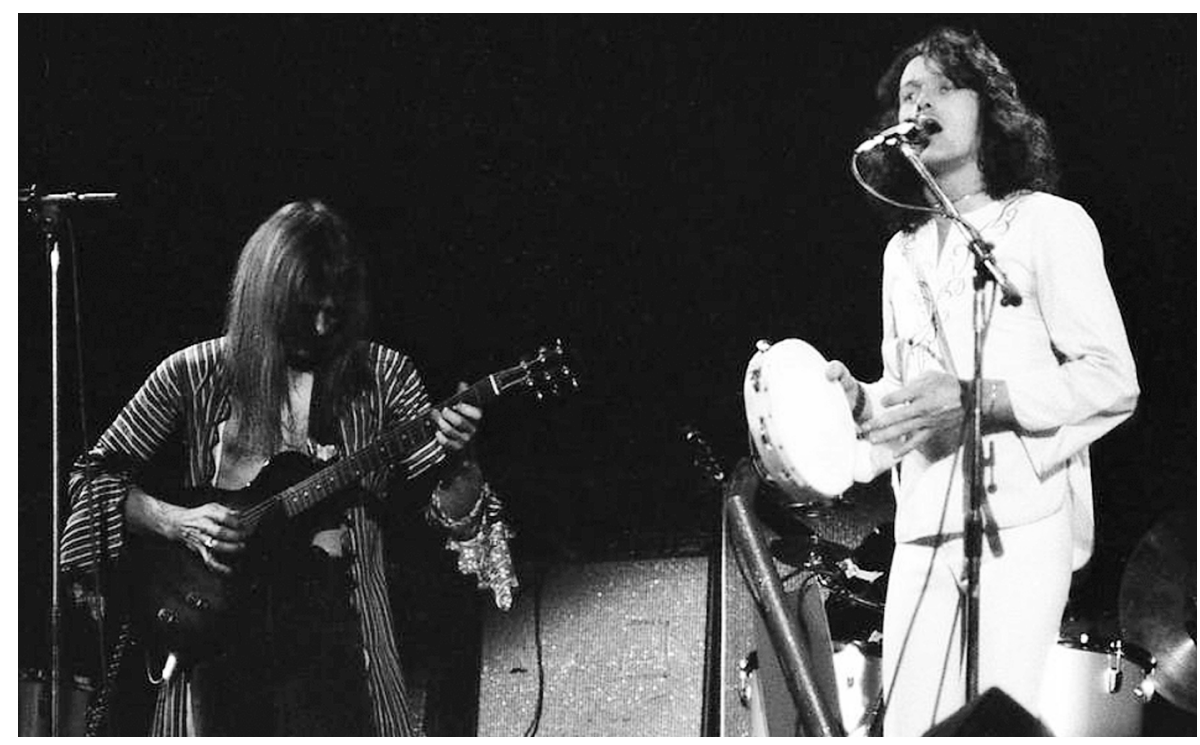

Imagen 9. Hunter-Desports (1974): El grupo Yes interpretando el disco Tales from Topographic Oceans.

Dentro de estas historias propias cabe destacar en disco doble publicado en 1974 The Lamb Lies Down On Broadway del grupo británico Genesis, este disco cuenta la compleja historia de Rael un artista callejero puertorriqueño que entra a un misterioso mundo subterráneo donde varias pruebas lo esperan, con referencias claras a El Infierno de Dante o a la mitología egipcia. El héroe es seducido por tres mujeres con características de lagartos, después Rael, el protagonista, es castrado; pero logra salvar a su hermano de la muerte, que era su misión principal (Imagen 10).

La mitología y la historia clásica también tiene cabida, así el grupo alemán Eloy publica en 1977 Atlantis, en el que mezclan el mito de Poseidón y el de la Atlántida narrando la pérdida del paraíso de la Atlántida por la naturaleza violenta del ser humano, nuevamente con la advertencia distópica entre líneas.

Aunque bien es cierto que el formato predomina dentro del rock progresivo, también es adoptado por otros estilos como el glam rock, por ejemplo David Bowie con su The Rise and Fall of Ziggy Stardust and the Spiders from Mars publicado en 1971 y en el que se cuenta la historia de una estrella de rock extraterrestre que llega al planeta Tierra para brindar un mensaje de paz 


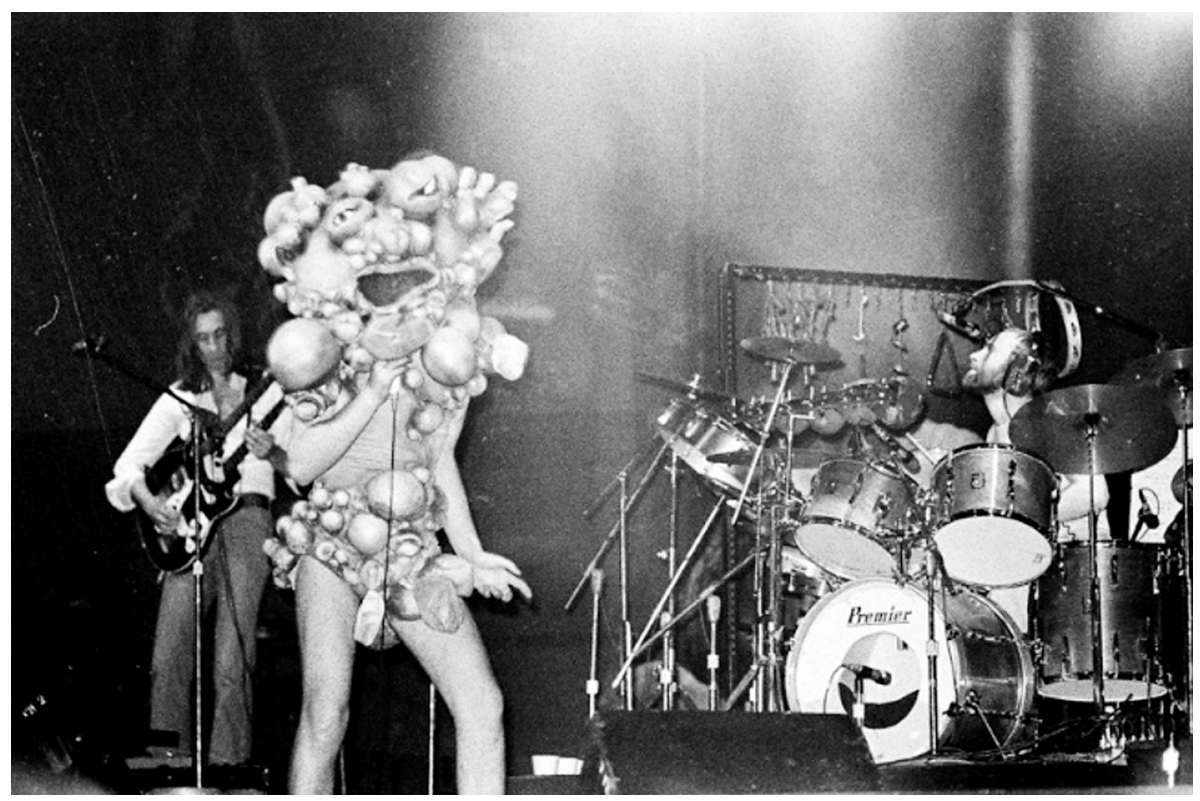

Imagen 10. Tony Morelli (1974): El grupo Genesis tocando en directo el disco The Lamb Lies Down On Broadway en el Auditorium Theatre de Nueva York.

y esperanza a la humanidad y termina corrompido por sus excesos y la fama que consigue entre los humanos; y la música disco, como Donna Summer que en su disco Four Seasons of Love (1976) narra las etapas de una relación amorosa (Imagen 11).

Otras temáticas fuera del ámbito del rock progresivo abarcan temas tan diversos como las relaciones amorosas entre señores maduros y mujeres jóvenes en Histoire de Melody Nelson y L'Homme à tête de chou del compositor y cantante francés Serge Gainsbourg publicados respectivamente en 1971 y 1976; en What's going on de Marvin Gaye publicado en 1971 que es relatado desde el punto de vista de un veterano de la guerra de Vietnam que al regresar a su país no ve más que desigualdad, sufrimiento, y corrupción.

Mención aparte merece Être Dieu: opéra-poème, audiovisuel et cathare en six parties de 1974 del músico francés Igor Wakhevitch y libreto del escritor barcelonés Manuel Vázquez Montalban quienes retoman una idea de 1927 de una ópera colaboración entre Salvador Dalí y Federico García Lorca. El propio 
Imagen 11. Casablanca Records, fotógrafo no acreditado (1977): Donna Summer en el estudio de grabación.

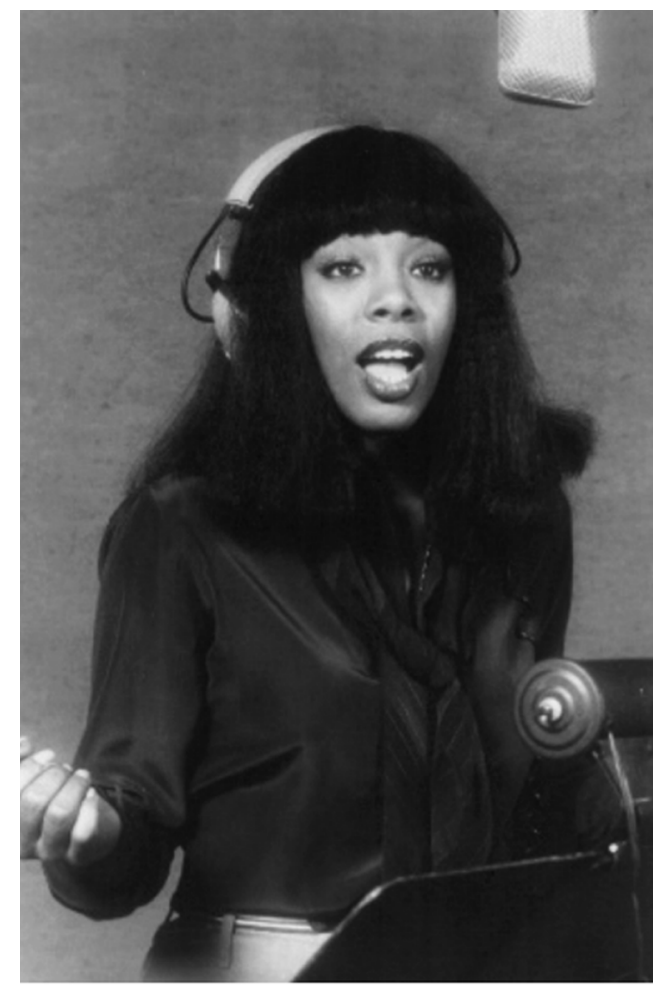

Salvador Dalí estuvo implicado en este trabajo, el cual presentaba como un reflejo de su propia personalidad, de hecho a la hora de grabarlo se negó a seguir el libreto de Vázquez Montalban.

\section{Las sagas conceptuales}

Mención aparte merecen los grupos que desarrollan su propia cosmología e incluso desarrollan sagas como es el caso de Gong y Magma en Francia y Funkadelic-Parliament en EE.UU. Nos vamos detener en esto tres grupos pues son desarrollos especialmente particulares del estilo.

En el caso de los grupos Funkadelic-Parliament, ambos son desarrollos de las ideas del músico George Clinton, en sus obras la cultura psicodélica es mezclada con elementos propios de la cultura afroamericana y el afrofuturismo, 
dando lugar a discos en los que se deja sentir una gran ironía con respecto a la situación de los norteamericanos de origen africano en los EE.UU, así entre 1970 y 1979, el grupo desarrolla la P-Funk Mythology que consiste en una serie de temas, personajes e ideas recurrentes que están presentes en gran parte de la producción del grupo de aquellos años. La saga comienza narrando como el secreto del funk se guarda en las pirámides desde hace más de 5000 años y la llegada del Dr. Funkenstein para volver a esparcir el virus del funk, pero la situación se descontrola y en colaboración con el Pentágono y la Casa Blanca deberá desfunkear a la Tierra. En estos discos la utopía viene disfrazada de afrofuturismo (Rangel, 2016) y el funk, como forma de catarsis es el medio para conseguirlo.

Por su parte el grupo francés Gong, con el australiano Daevid Allen como principal creador de sus historias, desarrolla la trilogía de Flying Teapot (la Tetera Volante) en forma de tres discos publicados entre 1972 y 1974 que cuentan la historia de Zero el héroe y los doctores de la octava que transforman las formas de vida a través de la música mediante transmisión telepática. La historia comienza con una egiptóloga llamada Mista T. Being que vende un pendiente mágico a Fred el pescado, vendedor y coleccionista de teteras. Este no sabe que el pendiente puede comunicar con el Planeta Gong a través de una emisora pirata, la Radio Gnomo Invisible. Pronto recibe la llamada de los enanos de cabeza de macetero, los cuales van en teteras voladoras. En este caso la fraternidad interdimensional es una forma de utopía y las sustancias psicoactivas el medio para lograrlo (Imagen 12).

Caso aparte merece el grupo Magma, que no sólo desarrolla su propia saga, sino que lo hace en un idioma fonético propio, el Kobäia y mediante un estilo de música también propio, el Zeulh, mezcla de música progresiva con elementos del jazz y la música de Wagner. A través de tres movimientos Kobäia, Thesusz Hamtaahk y Ëmëhntëhtt-Ré, narran la historia del profeta Nebehr Güdahtt. La historia comienza cuando este dice a los habitantes de la Tierra que si quieren salvar sus vidas, deben abandonar el planeta y establecerse en el planeta Kobaïa. La gente no le cree y comienza a enfrentarse a él, pero poco a poco algunos comienzan a creerle y un grupo decide ir con él rumbo al planeta Kobaïa. En los siguientes episodios se cuenta como las descendientes de esos mismos colonos terminan enfrentados a los nuevos colonos. Aquí encontramos un pensamiento distópico evidente e incluso pesimista, ya que la búsqueda de la utopía extraterrestre se ve ahogada por los terrícolas humanos que buscan perpetuar su modelo de sociedad, no dejando el desarrollo de modelos alternativos de sociedad. 
Imagen 12. Tim Duncan (1974): Daevid Allen del grupo Gong tocando en directo en Hyde Park de Londres.

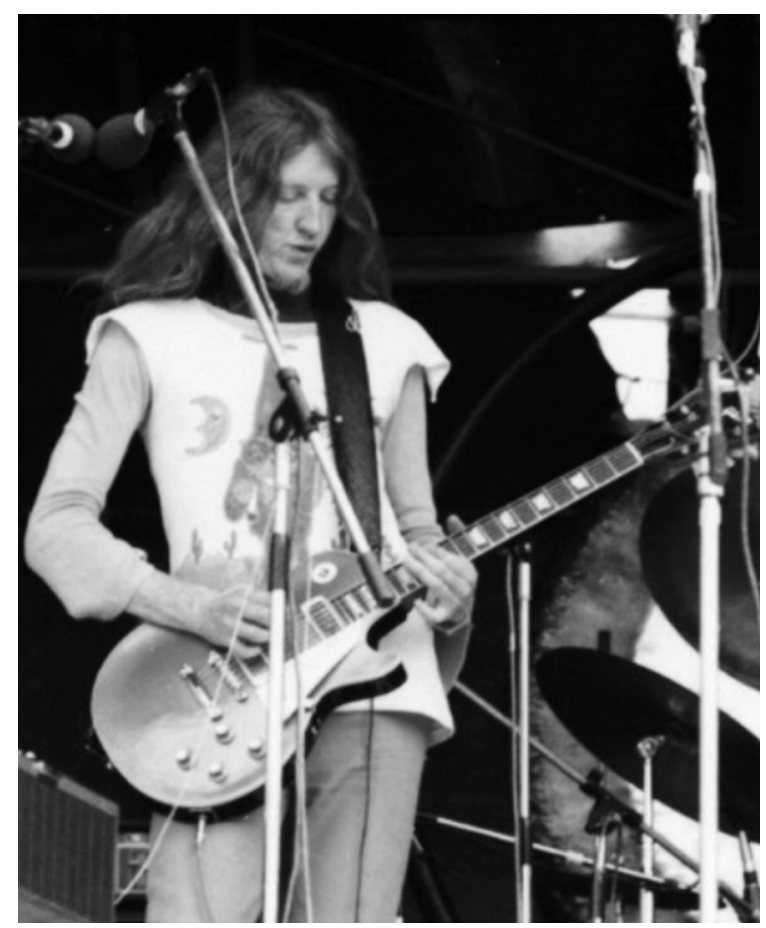

\section{Cambio de década y exportación del formato a otros estilos}

El final de la década de los setenta marca un descenso de la popularidad del formato del disco conceptual, pero ni mucho menos su fin. Así, si bien se siguen publicando discos conceptuales, el formato es adoptado por estos estilos, en el disco Nebraska de Bruce Springsteen, publicado en 1982, este retoma la tradición conceptual del folk político y habla del lado oscuro del sueño americano.

No obstante, el formato de disco conceptual se consolida especialmente en el estilo heavy metal, donde la temática fantástica predomina de forma evidente. Durante la década de los años ochenta, prácticamente todos los grupos de éxito del estilo como Iron Maiden, Dio o Manowar dan continuidad a las premisas de los grupos de la década anterior. Cabe indicar que con el cambio de valores generacionales la utopía y la distopía van siendo relegados a un lugar secundario y son sustituidos por fantasías sin un claro mensaje social y con una finalidad puramente evasiva. 
Dentro del contexto del disco conceptual de heavy metal encontramos también adaptaciones literarias, como Nightfall in Middle Earth de Blind Guardian, basado en El Silmarillion de J.R.R. Tolkien publicado en 1998; también encontramos relatos propios como el que cuenta Abigail del grupo norteamericano King Diamond, publicado en 1987 y en el que la trama tiene como protagonista a una pareja inglesa del siglo XIX que se muda a una antigua mansión. Cuando se establecen en el lugar el fantasma de la familia que habitó la mansión les advierte que su próxima hija cargará con el vengativo espíritu de un antiguo familiar.

Quizás el caso más difundido de disco conceptual de heavy metal sea $S e$ venth Son of the Seventh Son del grupo británico Iron Maiden y publicado en 1988. Este cuenta la historia de un vidente, el séptimo hijo de un séptimo hijo, que tiene facultades psíquicas como la clarividencia y otras mancias. Cada canción relata un tramo de la vida de este personaje, desde el nacimiento, el descubrimiento de sus poderes y su destino y su inminente muerte.

\section{CONCLUSIONES}

El disco conceptual es una expresión cultural genuinamente popular que paradójicamente toma elementos de la "alta cultura" para legitimarse, dando lugar a un particular producto que a diferencia de sus equivalentes literarios o cinematográficos, raramente ha tenido la consideración de obra artística, pese a las pretensiones iniciales de los músicos que comenzaron a desarrollar este tipo de discos.

En muchos casos los discursos utópicos y distópicos fueron la temática preferente, tomando en ambos casos la forma de lo que podríamos llamar "protesta fantástica" y en la que la denuncia toma forma de relato fantástico.

La omisión de discos conceptuales producidos en el territorio español, en donde el formato también tuvo bastante difusión, pero no tanta producción, responde primero a limitaciones de espacio y a que dada la amplitud del tema se ha preferido no abordarlo aquí, autores como García Peinazo (2016), García Salueña (2009a; 2009b) o Gómez-Font (2011) han abordado parte de la temática delimitándola a diferentes territorios de España.

En la década de los setenta el formato adquiere su plenitud artística muy vinculado al género progresivo, sin embargo, con los cambios de gustos musicales de la juventud, su público original, el formato quedó casi circunscrito al heavy metal, donde gozó de éxito y bastante difusión. En la actualidad los discos conceptuales siguen siendo muy populares y prácticamente se producen de todos los géneros musicales, siendo normalmente signo de madurez artística y de prestigio para el artista que lo realiza. 
En muchos casos el auge de internet ha hecho que muchos de los grupos pioneros aquí citados hayan vuelto a reunirse tras años separados para volver a grabar y dar conciertos y qué los discos que produjeron hallan vuelto a tener una insospechada redifusión que han hecho que las nuevas generaciones sigan cultivando este formato, ya sea como oyentes o como creadores.

\section{BIBLIOGRAFÍA}

AINSA, F. (1999): La reconstrucción de la utopía, Buenos Aires, Ediciones del Sol, $200 \mathrm{p}$.

ANDERTON, C. A. (2010): "Many-headed beast: progressive rock as European metagenre". Popular Music, 29, 3, 417-435.

ATTON, C. (2001): "'Living in the past'?: value discourses in progressive rock fanzines". Popular Music, 20, 1, 29-46.

AYNSLEY, J. A. (2001): Century of Graphic Design: Graphic Pioneers of the 20th Century, London, Mitchell Beazley, 256 p.

BALTAR, M (2011): “La utopía en el Rock”, en: Imaginarios utópicos en la cultura. De las utopías renacentistas a las posindustriales. Lucas E. Misseri y Romina Conti (eds.) Mar del Plata, Kazak Ediciones, 26-41.

BARTMANSKI, D. WOODWARD, I. (2015): "The vinyl: The analogue medium in the age of digital reproduction". Journal of Consumer Culture, 15, 1, 3-27.

BELL, D. (1977): Las contradicciones culturales del capitalismo. Madrid: Alianza, $246 \mathrm{p}$.

BOCOCK, R., PACHECO, B.B. (1995): El consumo, Madrid: Talasa, 192 p.

BRENNER, N. (2003). "La formación de la ciudad global y el re-escalamiento del espacio del Estado en la Europa Occidental post-fordista”. EURE (Santiago), 29 (86), 05-35.

BROUGHTON, F., BREWSTER, B. (2003): Manual del DJ: el arte y la ciencia de pinchar discos, Barcelona: Grupal Logistica y Distribucion, $287 \mathrm{p}$.

CARRASCO, A. (2016): "Discos conceptuales: el más allá de la música". Letras, 4, 65-69.

COVACH, J. R., FLORY, A. (2006): What's that sound? : an introduction to rock and its history. New York, WW Norton \& Company, $555 \mathrm{p}$.

ELIKER, M. (2001): "Concept Albums: Song Cycles in Popular Music", en: Bernhart, W., Wolf, W., Mosley, D. (ed.): Word and Music Studies: Essays on the Song Cycle and on Defining the Field. Proceedings of the Second International Conference on Word and Music Studies at Ann Arbor, Michigan, 1999. Rodopi, 253 p.

FARBER, D. (2002): "The intoxicated state/illegal nation: Drugs in the sixties counterculture. Imagine Nation: The American Counterculture of the 1960s and '70s", en: Braunstein, P., Doyle, M. W. (Ed.). Imagine nation: the American counterculture of the 1960s and '70s, New York, Routledge, 17-40. 
FRANCESCUTTI, P. (2004): La pantalla profética, Madrid: Cátedra, 336 p.

FRITH, S., (1988):" El arte frente a la tecnología. El extraño caso de la música popular". Papers. Revista de Sociología, 29, 178-196.

FRITH, S. (2001): "Hacia una estética de la música popular”. Las culturas musicales. Lecturas en etnomusicología, 413-435.

GARCÍA P., Diego (2016): "El rock andaluz: procesos de significación musical, identidad e ideología (1969-1982)". Revista de Musicología, 39, 2, 771-779.

GARCÍA, E. (2009): "Rock progresivo e identidades culturales en España: el caso de Asturcón”. Revista de Musicología, 591-602.

GARCÍA, E. (2009): "Rock progresivo español de los 70: análisis e interpretación de sus parámetros musicales". Cuadernos de música iberoamericana, 18, 187-208.

GÓMEZ-FONT, A. (2011): Barcelona, del rock progresivo a la música layetana y Zeleste, Lleida, Editorial Milenio, $132 \mathrm{p}$.

HEATH, J., POTTER, A. (2005). Rebelarse vende. El negocio de la contracultura. Madrid: Taurus. 417 p.

HEGARTY, P., HALLIWELL, M. (2011): Beyond and before: Progressive rock since the 1960s. New York, Continuum, $318 \mathrm{p}$.

HERNÁNDEZ, Esteban (2006). “Subversión y cultura pop”. Dirigido, 354, p. 26-28.

HERRERA, B. (2017). "Cultura y contracultura: observaciones periféricas". Realidad: Revista de Ciencias Sociales y Humanidades, 108, 273-283.

HORMIGOS, J., CABELLO, A. (2004): "La construcción de la identidad juvenil a través de la música”. Revista Española de Sociología, 4, 1, 259-270.

JOSEPHSON, N. S. (1992): "Bach meets Liszt: traditional formal structures and performance practices in progressive rock". The Musical Quarterly, 76, 1, p. 67-92.

LETTS, M. T. (2010): Radiohead and the Resistant Concept Album: How to Disappear Completely. Bloomington, Indiana University Press, 235 p.

LÓPEZ, J. A. (2014). "El acceso a la información en la economía de red y su impacto en la industria discográfica". Revista Luciérnaga, 6, 11, 52-62.

MACAN, E. (1997): Rocking the classics: English progressive rock and the counterculture. New York, Oxford University Press, 304 p.

MARTIN, B. (2015): Listening to the Future: The time of progressive rock, 1968-1978, Chicago, Open Court, 356 p.

MCKNIGHT-TRONTZ, J. (1999): Exotiquarium: Album Art from the Space Age. Londres: Griffin, 128 p.

MORO, T. (2016): Utopia. Barcelona, Ariel, 304 p.

MEDEL, I. L. (2014): "Muerte y resurrección de la portada de discos". Index. Comunicación, 4, 1, p. 37-58.

PAPALLINI, (2017): "El Buen Vivir, entre las tácticas del consumo y las cosmogonías ancestrales”. Chasqui: Revista Latinoamericana de Comunicación, 134, págs. 43-59.

PATMORE, D,. (2009): "Selling Sounds: Recordings and the Record Business" en: Cook N, Clarke E, Leech-Wilkinson D, et al. (eds.). The Cambridge Companion to Recorded Music. Cambridge: Cambridge University Press, 120-139. 
PÉREZ, C. (2018): "Rock y modernidad. El rock como campo de producción cultural a través del caso de los Kinks". [en línea]. Consultado el 23 de abril de 2018 en: https://bit.ly/2I4gxBe

RANGEL, E. (2016): “Afrofuturismo e questões políticas do negro na ficção científica”. Revista de Audiovisual Sala, 206, 5, 129-148.

RHODES, C. (2007) "Outside the Gates of Eden: Utopia and Work in Rock Music". Group \& Organization Management, 32, 1, 22-49.

RODRÍGUEZ, C. (2010): “Los lugares de la ciencia ficción”. Pliegos de Yuste, 11-12, 145-150.

RODRÍGUEZ, E. F. (2014): "Más allá de la música análisis de la narrativa transmedia en el álbum conceptual Mylo Xyloto de Coldplay". Tesis de Licenciatura. Universidad Javierana, Facultad de Comunicación y Lenguaje, Bogotá. Consultado el 23 de abril de 2018 en: https://bit.ly/2HFyQx5

ROMANÍ, O. SEPÚLVEDA, M. "Estilos juveniles, contracultura y política”. Polis [En línea], 11, 2005, Publicado el 27 agosto 2012, consultado el 12 octubre 2019. URL: http://journals.openedition.org/polis/5769

ROSE, P. (2015): Roger Waters and Pink Floyd: The Concept Albums. Teaneck: Fairleigh Dickinson University Press, 278 p.

RUBIO, J., KANELLIADOU, V. (2009). "Las imágenes de la contracultura y su apropiación neocapitalista como apariencia: la rebeldía como valor de consumo". Congreso Internacional Imagen y Apariencia, Murcia. 19 al 21 de noviembre de 2008. Recuperado de http://bit.ly/2njEVDP

SCARUFFI, P. (2003): A history of rock music: 1951-2000. New York: iUniverse, 553 p. SEDLÁČKOVÁ, R. (2015): The Rise of the Concept Album: Rock Turns Complex. Univerzita Palackého V Olomouci. Filozofická fakulta .Consultado online el 23 de abril de 2018 en: https://bit.ly/2Fwilh5

SHUTE, G. (2013): Concept Albums. Los Ángeles: Investigations Publishing, 182 p. USÓ-ARNAL, J. C. (2010): "Historia de la psicodelia y de algunos intelectuales influenciados por el LSD", Revista Replicante. Consultado online el 23 de abril de 2018 en: https://bit.ly/11H2MZc 